\title{
Palliative CT-Guided Cordotomy for Medically Intractable Pain in Patients with Cancer
}

\author{
(D)T.M. Shepherd, (D) M.J. Hoch, (DB.A. Cohen, (D) M.T. Bruno, (D) E. Fieremans, (D) G. Rosen, DD. Pacione, and (D) A.Y. Mogilner \\ O
}

\begin{abstract}
SUMMARY: Palliative cervical cordotomy can be performed via percutaneous radiofrequency ablation of the lateral $\mathrm{Cl}-2$ spinothalamic tract. This rare procedure can be safe, effective, and advantageous in mitigating medically intractable unilateral extremity pain for selected patients with end-stage cancer. This report reviews the indications, techniques, risks, and potential benefits of cordotomy. We describe our recent experience treating 3 patients with $\mathrm{CT}$-guided $\mathrm{Cl}-2$ cordotomy and provide the first characterization of spinal cord diffusion MR imaging changes associated with successful cordotomy.
\end{abstract}

U to $50 \%$ of patients with cancer have undertreated pain ${ }^{1}$ and continue to experience pain even after oral and intrathecal therapy are maximized. ${ }^{2,3}$ Intrathecal opioid administration can provide potent anesthesia but requires an operation with general anesthesia, regular medical follow-up, restricts patient mobility, and increases infection risks. These requirements may be detrimental to quality of life for patients with end-stage cancer. In such patients, percutaneous CT-guided C1-2 cordotomy can provide immediate pain relief by selective ablation of the lateral spinothalamic tract that transmits pain, temperature, and deep touch sensation. This procedure is inexpensive and does not require an operating room, hospitalization, or outpatient follow-up. Cordotomy can reduce oversedation and memory disturbance associated with high-dose opioid therapy, thus enabling patients better interpersonal interactions at the end of their lives. Two recent series outside North America reported that patients with endstage cancer with extremity pain experienced $40 \%-83 \%$ increases

\footnotetext{
Received June 16, 2016; accepted after revision August 28.

From the Department of Radiology (T.M.S., M.J.H., B.A.C., M.T.B., E.F.), Center for Advanced Imaging Innovation and Research (T.M.S., E.F.), and Departments of Medicine (G.R.) and Neurosurgery (D.P., A.Y.M.), New York University, New York, New York.

Timothy Shepherd received research support from the National Institute of Aging (NIH 1K23 AG048622-01). This work was supported, in part, by the Center for Advanced Imaging Innovation and Research and the National Institutes of Health National Institute of Biomedical Imaging and Bioengineering Biomedical Technology Resource Center (grant P41EB017183).

Please address correspondence to Timothy Shepherd, MD, PhD, Department of Radiology, New York University, 660 First Ave, Room 226, New York, NY 10016; e-mail: timothy.shepherd@nyumc.org

- Indicates open access to non-subscribers at www.ajnr.org

E Indicates article with supplemental on-line tables.

Indicates article with supplemental on-line photos.

http://dx.doi.org/10.3174/ajnr.A4981
}

in Karnofsky Performance Status and 83\%-86\% reductions in pain immediately after cordotomy. ${ }^{4,5}$ Pain relief was sustained for 6 months in most patients. ${ }^{5,6}$ Furthermore, there is a GRADE $1 \mathrm{c}$ recommendation ${ }^{7}$ for cordotomy to treat patients with cancer with poorly controlled pain. ${ }^{8}$

The CT-guided cordotomy procedure was previously described in the neurosurgery literature. ${ }^{4,9-11}$ Fig 1 and On-line Table 1 characterize the key relevant cervical spinal cord anatomy for understanding the procedure. The Table provides a summary of the ideal patient, absolute and relative contraindications for the procedure. The risk/benefit ratio ${ }^{6}$ of the procedure has improved with CT myelography image guidance, dynamic real-time electrode impedance measurements, and confirmation of electrode position via stimulation. In a recent series, $<3 \%$ of patients experienced temporary paresis, ataxia, dysesthesia, hypotension, or urinary retention. ${ }^{4}$ Cordotomy also has been performed safely in a child. ${ }^{12}$

Recent improvements in pain management have reduced the need for cordotomy to the point that the neurosurgery community is concerned that expertise in this procedure is disappearing. ${ }^{8-10,13}$ Only 3 medical centers in the United States have reported performing cordotomy during the past decade. ${ }^{12,14-17}$ Yet, a subset of patients with end-stage cancer with persistent incapacitating extremity pain not relieved by medical and intrathecal therapy could benefit from cordotomy if it were offered. Most interventional neuroradiologists have more experience than neurosurgeons in performing CT-guided ablative procedures and thus can help with these procedures as part of a multidisciplinary team. Here, we provide a summary of the procedure based on our recent experiences.

\section{CT-Guided Cordotomy}

The procedure first requires a cervical myelogram. For C1-2 puncture, the needle is directed toward the lateral cervical spinal 
cord anterior to the dentate ligament (On-line Fig 1). The spinothalamic tract has a ventromedial-to-dorsolateral axis of somatotopy. For intractable lower extremity pain, the needle is directed 1-2 $\mathrm{mm}$ anterior to the ligament to target the dorsolateral portion, whereas for upper extremity pain, the needle is directed 2-3 $\mathrm{mm}$ anterior to the ligament to target the ventromedial portion (Fig 1). After the outer needle has penetrated the tented dura, ${ }^{18}$ the stylet is exchanged for the inner electrode (Cosman Medical, Burlington, Massachusetts), which has demarcations to precisely control electrode extension beyond the needle. Electrical impedance measurements from the electrode tip provide real-time feedback of anatomic location. Impedance is $<200 \Omega$ for CSF, $<400$ $\Omega$ for pial surface, and $>700 \Omega$ for cord parenchyma. Once the electrode appears correctly positioned by CT, sedation is removed and the functional position is confirmed with stimulation. With high-frequency sensory stimulation $(50-100 \mathrm{~Hz}, 0.2-1.5 \mathrm{~V})$, patients should report warmth that increases to a burning sensation in the symptomatic contralateral extremity. ${ }^{9}$ Voltage is slowly increased because $0.2 \mathrm{~V}$ is often sufficient for confirming the correct electrode position. Next, the patient is observed during low-frequency motor stimulation $(2-5 \mathrm{~Hz}, 0.2-1.5 \mathrm{~V})$, which ideally does not provoke a motor response. Trapezius contractions suggest that the electrode tip is too deep and stimulating the ventral horn neurons, whereas ipsilateral lower extremity movements indicate that the electrode is too posterior in the corticospinal tract. Once the elec-

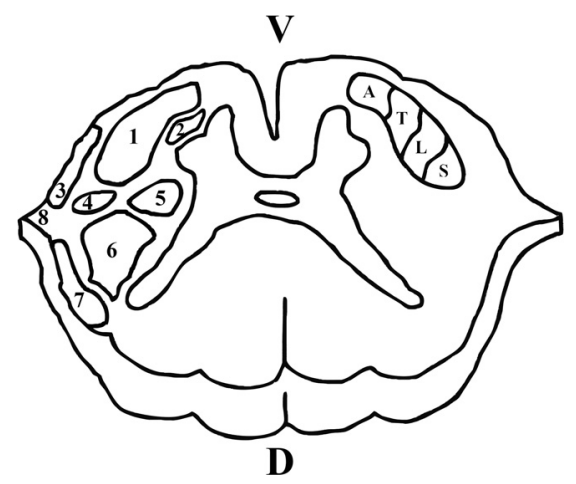

FIG 1. Schematic for the relevant functional anatomy of the axial cervical spinal cord when performing $\mathrm{Cl}-2$ cordotomy ( $\mathrm{V}$ indicates ventral; and D, dorsal). Important ventral and lateral white matter pathways include the lateral spinothalamic tract (1), ventral reticulospinal tract (2), ventral spinocerebellar tract (3), lateral reticulospinal tract (4), rubrospinal tract (5), lateral corticospinal tract (6), dorsal spinocerebellar tract (7), and dentate ligament (8). Furthermore, it is important to understand the somatopic organization of the lateral spinothalamic tract delineated on the opposite side. A indicates arm; T, trunk; L, leg; and S, sacrum. Please also see the Table. trode position appears acceptable, a test ablation is obtained with the tip heated to $80^{\circ} \mathrm{C}$ for 60 seconds, then the patient is reassessed. Assuming that patient-reported sensory changes are acceptable, 2 additional radiofrequency ablations are performed. The patient must be sedated throughout the ablations. The procedure requires $2-3$ hours for completion; if available, CT fluoroscopy could reduce this time, but the dominant time factor is alternating patient sedation. The procedure-related CT radiation dose was not a primary concern for terminally ill patients, but should be within normal limits. Afterward, we monitored patients overnight for changes in pain control, limb strength or ataxia, respiratory status, bowel or bladder function. Patients then were followed as outpatients by their oncologist.

\section{Individual Cases}

Case 1. A 52-year-old man with right pelvic osteosarcoma presented with severe lancinating hip pain not relieved by high doses of methadone and hydromorphone. Intrathecal narcotics and bupivacaine did not relieve his pain. A myelogram was obtained via direct injection into the intrathecal pump reservoir. Electrode placement was challenging because the patient rotated his head to the left during the procedure, but after confirmation of the correct electrode position with stimulation, left C1-2 dorsolateral spinothalamic tract radiofrequency ablation was performed without complications. The patient immediately noticed pain relief and was now comfortable moving himself independently onto the hospital bed from the scanner. Marked improved function and pain relief were sustained until the patient died from complications of pulmonary metastases 2 months later.

Case 2. A 59-year-old woman with right pelvic leiomyosarcoma presented with burning, aching pain in the right buttock, hip, and thigh not relieved by high doses of gabapentin, methadone, fentanyl, or hydromorphone. Intravenous fentanyl was effective, but "knocked her out completely." The intrathecal pump was deferred because of her infection risk from chemotherapy immunosuppression. A myelogram was obtained by lumbar puncture. Initial electrode placement resulted in unintended right upper extremity sensory stimulation, but after we repositioned the electrode, left C1-2 dorsolateral spinothalamic tract radiofrequency ablation was performed without complications (Fig 2). The patient no longer experienced right lower extremity pain but remained concerned about her persistent right lower extremity numbness, an expected result of the procedure. The patient died from systemic disease 5 months later.

Case 3. A 67-year-old woman with C7-T2 vertebral body metastases from esophageal cancer presented with severe right upper ex-

\section{Summary of ideal patient for cordotomy, contraindications, and specific additional material risks to the procedure}

\begin{tabular}{|c|c|c|}
\hline Ideal Patient & Contraindications & Additional Risk \\
\hline $\begin{array}{l}\text { Unilateral nociceptive pain from } \\
\text { extremity }\end{array}$ & Bilateral upper extremity pathology & Ondine's curse (apnea during sleep) if bilateral ablation \\
\hline $\mathrm{pO}_{2}>80 \%$ on room air & Severe pulmonary dysfunction & Insufficient reserve to tolerate decreased function \\
\hline Life expectancy between 3 and 12 mo & Survival $<3 \mathrm{mo}^{\mathrm{a}}$ or $>12 \mathrm{mo}$ & Deafferentation pain $\geq 6$ mo after procedure \\
\hline Normal ICP & Intracranial metastasis and/or mass effect & Brain herniation during procedure \\
\hline Absence of psychiatric comorbidities & Opiate dependence or emotional problems & Persistent pain control problems after cordotomy \\
\hline Intact autonomic system & Sympathetic dysfunction ${ }^{\mathrm{a}}$ & Hypotension, Horner syndrome, bladder dysfunction \\
\hline Comfortable in supine position & Orthopnea $^{a}$ & $\begin{array}{l}\text { Inability to be supine long enough to complete } \\
\text { procedure }\end{array}$ \\
\hline
\end{tabular}

Note: $-\mathrm{pO}_{2}$ indicates partial pressure of oxygen; ICP, intracranial pressure.

${ }^{\text {a }}$ Relative contraindication. 


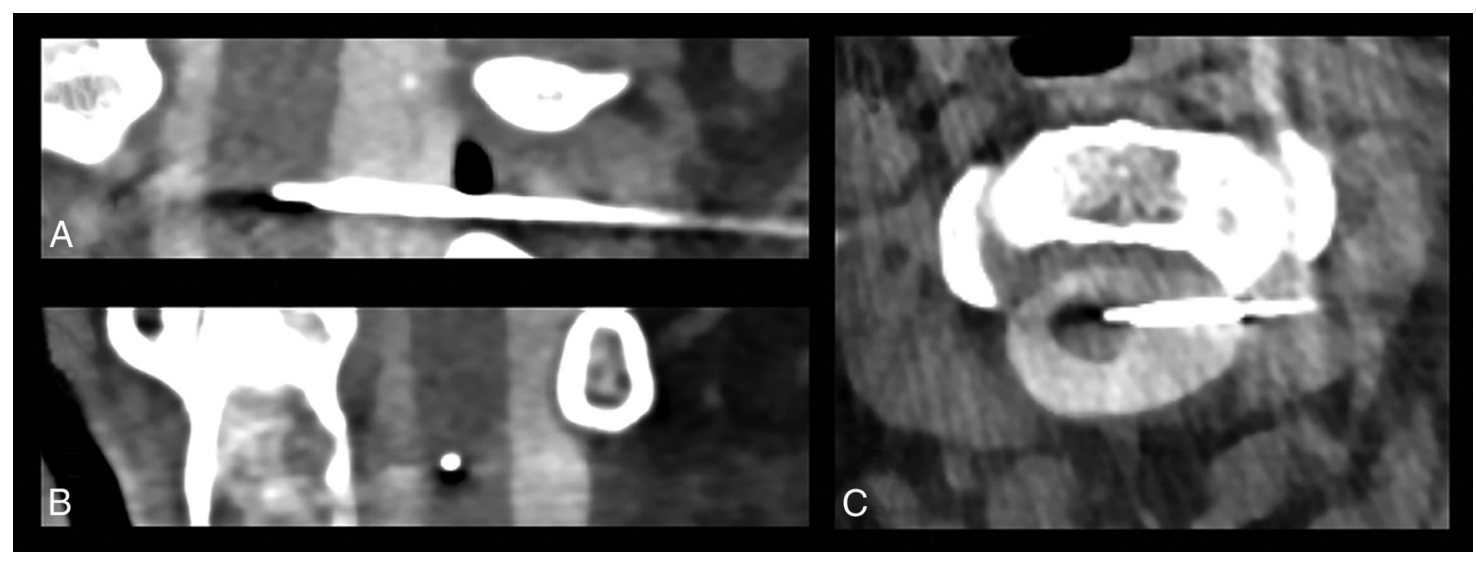

FIG 2. Coronal $(A)$, sagittal $(B)$, and axial $(C)$ reformats of the $C T$ myelogram demonstrate outer needle and inner electrode placement immediately before completion of a left lateral $\mathrm{Cl}-2$ cordotomy via radiofrequency ablation. The outer needle was placed into the thecal space near the pial surface of the cord approximately $2 \mathrm{~mm}$ ventral to the dentate ligament. The electrode was then advanced into the CSF, pia mater, and spinal cord with real-time monitoring of dynamic electrical impedance changes. Multimodal data, including the CT images, confirmed that the electrode was in the left spinothalamic tract. Note that the upper cervical cord is displaced to the right (we observed this in all 3 cases).

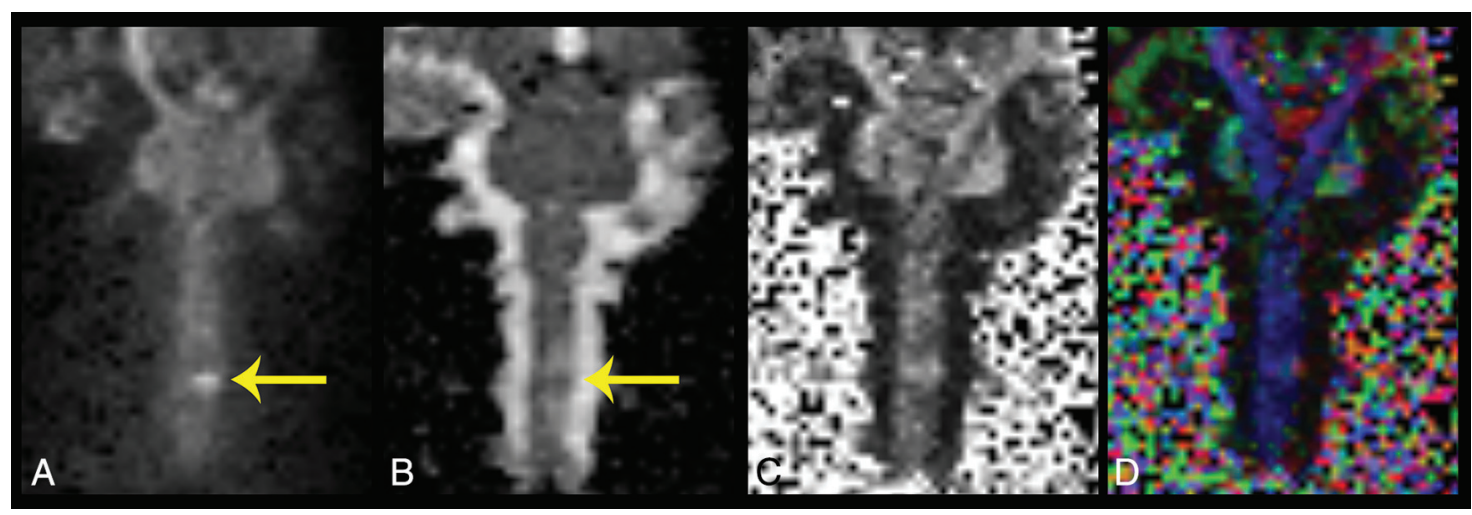

FIG 3. Coronal diffusion trace $(A)$, apparent diffusion coefficient $(B)$, fractional anisotropy $(C)$, and color-encoded fractional anisotropy maps $(D)$ of the cervical cord 48 hours after technically successful CT-guided left Cl-2 cordotomy. There is a small focus of hyperintensity on the diffusion trace image with corresponding reduced diffusion indicative of focal cytotoxic edema (arrow) and more extensive surrounding vasogenic edema. Manual ROI quantitation of these diffusion changes is summarized in On-line Table 2.

tremity stabbing pain not controlled by high doses of gabapentin, methadone, and morphine. A myelogram was obtained by CTguided cisternal puncture. Initial electrode placement resulted in visible trapezius contractions during motor stimulation. After the electrode penetration was reduced $1 \mathrm{~mm}$, muscle contractions were not observed during repeat stimulation, and left C1-2 ventromedial spinothalamic tract radiofrequency ablation was performed without complications. A contrast MRI with diffusion (20 directions, $b=1000 \mathrm{~s} / \mathrm{mm}^{2}$ ) was performed 2 days later to characterize the ablation (Fig 3 and On-line Fig 2). Five months later, the patient's right upper extremity pain remains well-controlled by using a methadone regimen that had been ineffective before cordotomy.

\section{DISCUSSION}

We successfully performed 3 CT-guided palliative C1-2 spinal cordotomies without complications. Our subjects all experienced meaningful postcordotomy improvement in pain control. Our series is limited in size, but the results and safety corroborate 2 larger cohorts reported from outside North America ${ }^{4,5}$ and case reports from 3 institutions in the United States documenting CTguided cordotomies during the past decade. ${ }^{12,14-17}$ Needle placement by using CT myelography with dynamic real-time imped- ance feedback during electrode penetration increases the safety of modern cordotomy. Radiofrequency ablation also enabled us to physiologically confirm the target with patient-reported feedback during motor and sensory stimulation. Another key factor for success is selecting the correct patient-ideally this is a patient with end-stage cancer with medically refractory nociceptive pain from a single extremity (other major sources of pain should be excluded).

Several groups have performed myelography during the C1-2 puncture, but published images ${ }^{4,12,14,15}$ suggested limited redistribution of viscous contrast because the patient cannot be moved. ${ }^{5}$ We preferred a separate myelogram injection to plan the trajectory to the spinothalamic tract relative to the skin entry, lateral C1-2 window, and intrathecal spinal cord position. Furthermore, we found that a CT-guided cisternal myelography has practical advantages once contrast is instilled and the needle is removed; alternating the patient between supine, right and left decubitus positions gave excellent myelographic contrast in $<5$ minutes (Fig 2) ${ }^{18}$ without moving the patient off the table or removing monitoring equipment for sedation.

We also used volumetric 3D T2 MR imaging multiplanar re-

AJNR Am J Neuroradiol 38:387-90 Feb 2017 www.ajnr.org

389 
constructions to plan the procedure. A previous study reported precordotomy cervical spine MR imaging for frameless intraoperative stereotaxy. ${ }^{19} \mathrm{MR}$ imaging may be contraindicated in some patients but helped us identify individual-specific anatomic corridors to reach the desired part of the spinothalamic tract before the procedure (On-line Fig 1). A previous study found that vertebral arteries overlaid the C1-2 spinal canal in $31 \%$ of cases. ${ }^{20}$ In case 3, preprocedural 3D T2-weighted structural MR imaging identified the left vertebral artery lateral to the canal just anterosuperior to the planned trajectory.

For all 3 cases, we observed lateral displacements of the spinal cord away from the electrode (Fig 2). Cord displacement up to 0.5 $\mathrm{cm}$ has been reported historically ${ }^{21}$ and also can be observed in recent CT-guided cordotomies. ${ }^{5,11,12,15}$ We observed no problems in our subjects due to spinal cord displacement, and the cord in subject 3 had returned to a normal position on MR imaging 2 days later (On-line Fig 2).

Postprocedural MR imaging demonstrated focal enhancement at the electrode ablation zone in the anteromedial spinothalamic tract. More extensive surrounding edema (On-line Fig 2) was similar to observations in a previous report. ${ }^{14}$ We characterized diffusion changes associated with cordotomy (Fig 3 and Online Table 2). Compared with the contralateral homolog, diffusivity and fractional anisotropy for the ablative lesion decreased $12 \%$ and $30 \%$, respectively. A $13 \%$ increase in radial diffusivity was attributed to electrode penetration trauma in the transverse plane, while a $33 \%$ reduction in axial diffusivity was attributed to axonal injury from the ablation. It would be informative to study the evolution of diffusion changes after a precise cord injury at a specific time, but it is challenging to obtain MR imaging in these patients. A previous study demonstrated focal spinal cord atrophy in a patient 41 years after cordotomy. ${ }^{15}$

A subset of patients with end-stage cancer who continue to experience extremity pain even with maximal medical and/or intrathecal therapy $^{1-3}$ could benefit from CT-guided cordotomy, but only 3 medical centers in North America have reported performing this procedure during the past decade. ${ }^{12,14-17}$ Our small series corroborates that this relatively precise, ablative procedure can be safe and effective in reducing both oversedation and the need for medical follow-up for carefully selected patients with end-stage cancer. ${ }^{4,5} \mathrm{Un}$ deruse of cordotomy may be due to unfamiliarity, reluctance, and/or insufficient experience to perform palliative ablative procedures safely and effectively, even in the neurosurgery community. ${ }^{8-10,13}$ Many neuroradiologists frequently perform similar CT-guided spine procedures and ablations. These neuroradiologists can provide the missing expertise to safely perform this procedure as part of a multidisciplinary team for improved patient care.

Disclosures: Timothy M. Shepherd_-UNRELATED: Grants/Grants Pending: industrysponsored study unrelated to this article, Comments: Principal Investigator, integration of advanced MRI into planning and monitoring for patients with intracranial metastases undergoing radiosurgery; BrainLab AG (academic-industry partnership through New York University Office of Industrial Liaison) (June 1, 2015, to May 31, 2017)*; Patents (Planned, Pending, or Issued): 3 patents filed for medical devices not discussed in the article, Comments: Patent Cooperation Treaty Patent Application No. PCT/US2015/020426, filed March 13, 2015, entitled "Position Guidance Device with Bubble Level"; US Provisional Patent Application No. 62/243,478, filed October 19, 2015, entitled "Electronic Position Guidance Device with Real-Time Auditory and Visual Feedback"; US Provisional Patent Application No. 62/307,257, filed March 11, 2016, entitled "Pseudo-Tissue for Securing, Protecting and Adjusting the Position of
Percutaneous Medical Devices."* Donato Pacione-UNRELATED: Consultancy: Medtronic, Comments: paid an honorarium for a discussion group on anterior cervical discectomy and fusion. *Money paid to the institution.

\section{REFERENCES}

1. Deandrea S, Montanari M, Moja L, et al. Prevalence of undertreatment in cancer pain: a review of published literature. Ann Oncol 2008;19:1985-91 CrossRef Medline

2. Newsome S, Frawley BK, Argoff CE. Intrathecal analgesia for refractory cancer pain. Curr Pain Headache Rep 2008;12:249-56 CrossRef Medline

3. Grossman SA, Staats PS. Current management of pain in patients with cancer. Oncology (Williston Park) 1994;8:93-107; discussion 107, 110, 115 Medline

4. Kanpolat Y, Ugur HC, Ayten M, et al. Computed tomography-guided percutaneous cordotomy for intractable pain in malignancy. Neurosurgery 2009;64(3 suppl):ons187-93; discussion ons193-94 Medline

5. Raslan AM. Percutaneous computed tomography-guided radiofrequency ablation of upper spinal cord pain pathways for cancerrelated pain. Neurosurgery 2008;62(3 suppl 1):ons226-33; discussion ons233-34 Medline

6. Sindou M, Jeanmonod D, Mertens P. Ablative neurosurgical procedures for the treatment of chronic pain. Neurophysiol Clin 1990;20: 399-423 CrossRef Medline

7. Atkins D, Best D, Briss PA, et al; GRADE Working Group. Grading quality of evidence and strength of recommendations. BMJ 2004; 328:1490 CrossRef Medline

8. Raslan AM, Cetas JS, McCartney S, et al. Destructive procedures for control of cancer pain: the case for cordotomy. J Neurosurg 2011; 114:155-70 CrossRef Medline

9. Binder DK, Barbaro NM. Cordotomy. In: Follett K, ed. Neurosurgical Pain Management. Philadelphia: Saunders; 2004:165-71

10. Konrad P. Dorsal root entry zone lesion, midline myelotomy and anterolateral cordotomy. Neurosurg Clin N Am 2014;25:6997-22 CrossRef Medline

11. Rosenberg WS. Cordotomy for intractable malignant pain. In: Narang S, Ross EL, Weisheipl A, eds. Surgical Pain Management: A Complete Guide to Implantable and Interventional Pain Therapies. Oxford: Oxford University Press 2016:375-79

12. Reddy GD, Okhuysen-Cawley R, Harsh V, et al. Percutaneous CTguided cordotomy for the treatment of pediatric cancer pain. $J \mathrm{Neu}$ rosurg Pediatr 2013;12:93-96 CrossRef Medline

13. Fitzgibbon DR. Percutaneous CT-guided C1-2 cordotomy for intractable cancer pain. Curr Pain Headache Rep 2009;13:253-55 CrossRef Medline

14. Collins KL, Patil PG. Flat-panel fluoroscopy O-arm-guided percutaneous radiofrequency cordotomy: a new technique for the treatment of unilateral cancer pain. Neurosurgery 2013;72(1 suppl operative):27-34; discussion 34 CrossRef Medline

15. Collins KL, Taren JA, Patil PG. Four-decade maintenance of analgesia with percutaneous cordotomy. Stereotact Funct Neurosurg 2012; 90:226-72 CrossRef Medline

16. Viswanathan A, Bruera E. Cordotomy for treatment of cancer-related pain: patient selection and intervention timing. Neurosurg Focus 2013;35:1-4 CrossRef Medline

17. Bentley JN, Viswanathan A, Rosenberg WS, et al. Treatment of medically refractory cancer pain with a combination of intrathecal neuromodulation and neurosurgical ablation: case series and literature review. Pain Med 2014;15:1488-95 CrossRef Medline

18. Orrison WW, Eldevik OP, Sackett JF. Lateral C1-2 puncture for cervical myelopathy, part III: historical, anatomic, and technical considerations. Radiology 1983;146:401-08 CrossRef Medline

19. McGirt MJ, Villavicencio AT, Bulsara KR, et al. MRI-guided frameless stereotactic percutaneous cordotomy. Stereotact Funct Neurosurg 2002;78:53-63 Medline

20. Katoh Y, Itoh T, Tsuji H, et al. Complications of lateral C1-2 puncture myelography. Spine 1990;15:1085-87 CrossRef Medline

21. Taren JA, Davis R, Crosby EC. Target physiologic corroboration in sterotaxic cervical cordotomy. J Neurosurg 1969;30:569-84 CrossRef Medline 